existing options, there is still no general consensus on the choice and priority of the best intra-articular injection in knee osteoarthritis.

Objectives: Our study compare the short and long-term efficacy of the intra articular injections (IAIs) of hyaluronic acid (HA), platelet-rich plasma (PRP), plasma rich in growth factors (PRGF), and ozone in patients with knee osteoarthritis (OA). Methods: In this single-blinded randomized clinical trial, 238 patients with mild to moderate knee OA were randomized into4 groups of IAls: HA (3 doses weekly), PRP (2 doses with 3 weeks interval), PRGF ( 2 doses with 3 weeks interval), and Ozone (3 doses weekly). Our outcome measures were the mean changes from baseline until 2,6, and 12 months post intervention in scores of visual analog scale, Western Ontario and McMaster Universities Osteoarthritis Index (WOMAC), and Lequesne index. Results: A total of 200 patients enrolled final analysis. The mean age of patients was $56.9 \pm 6.3$ years, and69.5\% were women. In 2 months follow up, significant improvement of pain, stiffness, and function were seen in all groups compared to the baseline, but the ozone group had the best results $(P<0.05)$. In 6 month follow up HA, PRP, and PRGF groups demonstrated better therapeutic effects in all scores in comparison with ozone $(P<0.05)$. At the end of the 12th month, only PRGF and PRP groups had better results versus $\mathrm{HA}$ and ozone groups in all scores $(P<0.05)$. Despite the fact that ozone showed better early results, its effects begin to wear off earlier than other products and ultimately disappear in 12 months. Conclusion: Ozone injection had rapid effects and better short-term results after 2 months, but its therapeutic effects did not persist after 6 months and at the 6-month follow up, PRP,PRGF and HA were superior to ozone. Only patients in PRP and PRGF groups improved symptoms persisted for 12 months. Therefore, these products could be the preferable choices for long-term management.

References:

[1] Wang-Saegusa A, Cugat R, Ares O, Seijas R, Cuscó X, Garcia-Balletbó $M$. Infiltration of plasma rich in growth factors for osteoarthritis of the knee short-term effects on function and quality of life. Archives of orthopaedic and trauma surgery. 2011;131(3):311-7.

[2] De La Mata J. Platelet rich plasma.A new treatment tool for the rheumatologist?ReumatologíaClínica (English Edition). 2013;9(3):166-71.

[3] Raeissadat SA, Rayegani SM, Sedighipour L, Bossaghzade Z, Abdollahzadeh $\mathrm{MH}$, Nikray R, et al. The efficacy of electromyographic biofeedback on pain, function, and maximal thickness of vastus medialis oblique muscle in patients with knee osteoarthritis: a randomized clinical trial. Journal of pain research. 2018;11:2781.

[4] Lawrence RC, Felson DT, Helmick CG, Arnold LM, Choi H, Deyo RA, et al. Estimates of the prevalence of arthritis and other rheumatic conditions in the United States: Part II. Arthritis \& Rheumatism. 2008;58(1):26-35.

[5] Tehrani-Banihashemi A, Davatchi F, Jamshidi AR, Faezi T, Paragomi P, Barghamdi M. Prevalence of osteoarthritis in rural areas of I ran: a WHO-ILAR COPCORD study. International journal of rheumatic diseases. 2014;17(4):384-8.

[6] Rayegani SM, Raeissadat SA, Heidari S, Moradi-Joo M. Safety and effectiveness of low-level laser therapy in patients with knee osteoarthritis: a systematic review and meta-analysis. Journal of lasers in medical sciences. 2017;8(Suppl 1):S12.

Disclosure of Interests: None declared

DOI: 10.1136/annrheumdis-2020-eular.513

\section{AB0879 DOES BODY WEIGHT INFLUENCE THE KNEE INJURY AND OSTEOARTHRITIS OUTCOME SCORE IN PERSONS WITH SYMPTOMATIC KNEE OSTEOARTHRITIS?}

A. Ben Tekaya ${ }^{1}$, L. Rouached ${ }^{1}$, A. Slimi ${ }^{2}$, J. Galalou ${ }^{3}$, E. Bahlouli ${ }^{3}$ O. Saidane ${ }^{1}$, S. Bouden ${ }^{1}$, R. Tekaya ${ }^{1}$, I. Mahmoud ${ }^{1}$, L. Abdelmoula ${ }^{1} .{ }^{1}$ Charles Nicolle Hospital, Rheumatology, Tunis, Tunisia; ${ }^{2}$ Community Health Center, Kef, Tunisia; ${ }^{3}$ Physical and Rehabilitation Medicine Department, Djebel Oust, Tunisia

Background: Overweight is a major risk factor for the development and progression of knee osteoarthritis (OA). Weight loss for patients with knee OA has been associated with improvement in self-reported pain and function and is recommended by EULAR as part of the therapeutic management.

Objectives: The aim of the study was to evaluate the relation between overweight and functional impairment in adults with knee OA.

Methods: It was a prospective study conducted in a rheumatologic department over a 4 months period. Patients with symptomatic knee OA based on the ACR criteria, were included. A screening of body mass index (BMI) was carried out for all patients. It was categorized following the WHO classification into: normal $(<25 \mathrm{~kg} / \mathrm{m} 2$ ), overweight $(25$ to $<30$ ), obese (up to 30 ).

Pain level was evaluated using the Visual Analogue Scale (VAS). Function was assessed by the short form of the Knee injury and Osteoarthritis Outcome Score (KOOS-PS) (KOOS-PS scores to 0 representing no difficulty and 100 representing extreme difficulty). The patients' knee radiographies were graded according to Kellgren Lawrence criteria $(\mathrm{KL})$. The patients were allocated in two groups; as grade I-II KL (Group 1) and grade III-IV KL (Group 2).

Results: We included 143 patients with a mean age of $65.17 \pm 10.7$ years and $88.1 \%$ of women. Patients were from low socio-economic class in $30.8 \%$ of cases. Mean disease duration of the KOA was 5.4 years [3months-20 years] and mean BMI was $31.8 \pm 5.6 \mathrm{~kg} / \mathrm{m}^{2}$. Patients were with normal weight in $16.1 \%$, overweight in $19.6 \%$ and obese in $64.3 \%$

Knee OA was bilateral in $85.3 \%$ and other OA sites were associated in $37.8 \%$ of patients. Mean VAS pain of knee OA was $6.6 \pm 1.5$ and KOOS-PS was $48.8 \pm 16.5 / 100$. Concerning the radiographic damage; we found grade I-II (KL) in $22.6 \%$ and grade III-IV (KL) in $77.4 \%$

High BMI (BMl $\geq 25 \mathrm{~kg} / \mathrm{m}^{2}$ was not significantly associated with worse KOOS score $(p=0.9)$, more pain $(p=0.5)$ or an increasing severity of radiological knee osteoarthritis $(p=0.14)$. Moreover, the level BMI was not associated with the presence of other OA sites $(p=0.9)$ or a bilateral KOA $(p=0.07)$.

Conclusion: These data, from a subset of participants with symptomatic radiographic knee OA, demonstrate no correlation between obesity and pain, functional impairment and radiographic severity.

Acknowledgments: none

Disclosure of Interests: None declared

DOI: 10.1136/annrheumdis-2020-eular.5643

\section{AB0880 NEUROPATHIC PAIN IN PATIENTS WITH KNEE OSTEOARTHRITIS: PREVALENCE AND RELATED FACTORS}

A. Ben Tekaya ${ }^{1}$, L. Rouached ${ }^{1}$, A. Slimi ${ }^{2}$, O. Saidane ${ }^{1}$, S. Bouden ${ }^{1}$, R. Tekaya ${ }^{1}$, I. Mahmoud ${ }^{1}$, L. Abdelmoula ${ }^{1} .{ }^{1}$ Hospital Charles Nicolle, Rheumatology, Tunis, Tunisia; ${ }^{2}$ Community Health Center, Kef, Tunisia, Kef, Tunisia

Background: Discordance between radiographic and pain severity in osteoarthritis (OA) has led researchers to investigate other pain mechanisms, including neuropathic pain (NP). Recent meta-analysis concluded that NP prevalence in people with knee or hip OA was $23 \%$ [1].

Objectives: The primary objective of this study was to determine the prevalence of NP in patients with painful knee OA. Secondarily, we evaluated the relationship between NP and pain intensity, function and radiographic severity of knee OA. Methods: This cross-sectional study enrolled patients with knee OA (ACR criteria) from a rheumatology outpatient Hospital over a four-month period. Exclusion criteria were: knee surgery, chronic conditions of the nervous system, cognitive or psychiatric disorders. The patient's characteristics and pain severity using the Visual Analogue Scale (VAS) were evaluated. The NP was assessed accord ing to the Douleur Neuropathique 4 questionnaire (DN4) (arabic valid version). Functional impairment was estimated using the short form of the Knee injury and Osteoarthritis Outcome Score (KOOS-PS) (KOOS-PS scores to 0 representing no difficulty and 100 representing extreme difficulty). Radiographs were rated using the Kellgren Lawrence (KL) grade classification (I-IV). Statistical analysis was performed to find the factors closely related with NP.

Results: Ninety three patients with knee OA were included in the study. The mean age was $65.03 \pm 18.5$ years with a sex ratio of 0.08 . Mean duration of symptoms was 3.5 years [3months-20 years]. Concerning the marital status: $53.8 \%$ were married, $34.4 \%$ were widow and $10.8 \%$ were divorced. The majority of patients were illiterate $(65.6 \%)$ and only $2.2 \%$ went to university. Patients were from low socio-economic class in $37.6 \%$ of cases. At least one comorbidity was revealed for $90.3 \%$ of patients and their mean BMI was $31.6 \pm 6.3$ [19.9-52.3] Concerning the clinical features of the KOA, mean VAS pain was $6.6 \pm 1.6$ and KOOS-PS was $45.6 \pm 18.5$. Of the subjects, $22.6 \%$ have radiographic at grade II, $57 \%$ at grade III and $20.4 \%$ at grade IV based on $\mathrm{KL}$ grading.

The mean (SD) score by the study participants on the DN4 was $4.9 \pm 2.4$. The prevalence of NP (DN4 $\geq 4)$ was $71 \%$.

A DN4 score $\geq 4$ was significantly associated with the VAS pain $(p=0.00)$ and the KOOS-PS $(p=0.00)$ and the presence of comorbidity $(p=0.04)$. However, there was no significant relation between DN4 score and, age, sex, marital status socio economic class, level of education, $B M I$ and $K L$ grade $(p=0.7, p=0.08$, $p=0.7, p=0.3, p=0.7, p=0.7, p=0.6$ )

Conclusion: Our results highlight the high frequency of NP in patients with knee OA according to the DN4. Knee OA patients with NP encounter clinically relevant functional limitation. Thus, it is important to be aware of this neuropathic component to ensure appropriate management in the treatment of knee OA pain.

[1] French HP, Smart KM, Doyle F. Prevalence of neuropathic pain in knee or hip osteoarthritis: A systematic review and meta-analysis. Semin Arthritis Rheum. 2017;47(1):1-8

Acknowledgments: none

Disclosure of Interests: None declared

DOI: 10.1136/annrheumdis-2020-eular.3740 